\title{
Spatiotemporal Differentiation of Coupling and Coordination Relationship of Tourism-Urbanization-Ecological Environment System in China's Major Tourist Cities
}

\author{
Xia Xie ${ }^{1,2} \oplus$, Hui Sun ${ }^{1,2} \oplus$, Jun Gao ${ }^{1,2,3}$, Feifei Chen ${ }^{1,2}$ and Chunshan Zhou ${ }^{4, *} \mathbb{1}$ \\ 1 College of Tourism, Xinjiang University, Urumqi 830049, China; xiexia@xju.edu.cn (X.X.); \\ sunhui920@stu.xju.edu.cn (H.S.); gaoj63@mail.sysu.edu.cn (J.G.); chenfei@stu.xju.edu.cn (F.C.) \\ 2 Key Laboratory for Sustainable Development of Xinjiang's Historical and Cultural Tourism, \\ Xinjiang University, Urumqi 830046, China \\ 3 School of Tourism Management, Sun Yat-Sen University, Zhuhai 519000, China \\ 4 School of Geography and Planning, Sun Yat-Sen University, Guangzhou 510275, China \\ * Correspondence: zhoucs@mail.sysu.edu.cn
}

\section{check for}

updates

Citation: Xie, X.; Sun, H.; Gao, J.; Chen, F.; Zhou, C. Spatiotemporal Differentiation of Coupling and Coordination Relationship of Tourism-Urbanization-Ecological Environment System in China's Major Tourist Cities. Sustainability 2021, 13, 5867. https://doi.org/ $10.3390 /$ su13115867

Academic Editor: J. Andres Coca-Stefaniak

Received: 1 April 2021

Accepted: 20 May 2021

Published: 23 May 2021

Publisher's Note: MDPI stays neutral with regard to jurisdictional claims in published maps and institutional affiliations.

Copyright: (c) 2021 by the authors. Licensee MDPI, Basel, Switzerland. This article is an open access article distributed under the terms and conditions of the Creative Commons Attribution (CC BY) license (https:/ / creativecommons.org/licenses/by/ $4.0 /)$.

\begin{abstract}
Determining the coupling development mode and evolution process of the tourismurbanization-ecological environment system is of great significance in promoting high-quality and sustainable development of tourism and the urban economy. In this study, an evaluation index system of the tourism-urbanization-ecological environment system was established, and the spatiotemporal differentiation of the coupling and coordination relationship of the tourism-urbanization-ecological environment system was analyzed for 35 major tourist cities in China from 2009 to 2018. The results show that the comprehensive development indices of the tourism industry subsystem and urbanization subsystem of China's major tourist cities have steadily increased. The comprehensive development indices of large-sized and medium-sized cities in the east are relatively high. From 2009 to 2018, the coordination degree and coupling degree of the tourism-urbanization-ecological environment' system of 35 tourist cities showed an upward trend. The growth rate of the coupling coordination degree lags behind the growth rate of the coupling degree, and the overall system coordination level is still low. There are significant differences in the coupling degree and coupling coordination degree among the eastern, central, and western cities. This study offers both theoretical and practical implications for further equalizing the development level between the cities, as well as improving the overall coordination between the tourism industry, urbanization, and the ecological environment in China.
\end{abstract}

Keywords: tourism industry; urbanization; ecological environment; tourist city; coupling coordination model

\section{Introduction}

Urbanization refers to a long-standing process in the gradual population shift from rural to urban areas with increasing numbers of secondary and tertiary industries, resulting in the creation and expansion of cities. Accelerating urbanization has important implications for promoting economic development and social modernization and improving economic efficiency. The development of the urban economy will also stimulate employment and income level of residents and provide better urban infrastructure, thereby enhancing the wellbeing of the population. However, the rapid development of urbanization has not only concentrated various modern favorable factors but also social contradictions, including the contradiction between humans and nature and between economic development and environmental protection. In the early stage of urbanization, industrialization is often regarded as its main driving factor [1]. In many places in China, cities are agglomerated around heavy industry and industrial sites. Most existing urbanization development models in China are dominated by industrialization, which inevitably leads to many problems, 
such as environmental damage, similar local industrial systems, and the loss of traditional culture. Since the 1970s, developed countries such as the US, the United Kingdom, and France have taken the lead in completing the process of industrialization, thereby entering a period of transformational development. In these examples, the main force driving urbanization has gradually shifted from manufacturing and heavy industry to the service industry and cultural industry, of which leisure tourism forms a key component. Ecological environmental protection and sustainable urban development in the process of urbanization have also attracted increasing attention. In 2012, the Chinese government proposed the development of a new mode of urbanization, advocating for a form of urbanization that not only relies on manufacturing and heavy industry but also on other industries. This innovative urbanization development mode is known as multi-channel urbanization. The traditional urbanization mode emphasizes the speed of development over quality, which has led to many problems such as the destruction of the ecological environment in urban areas and the decline of the environment's carrying capacity, thereby restricting the sustainable development of cities. Therefore, the construction of ecological civilization and green sustainable development will be an essential part of the construction of new urbanization.

In 2015, The United Nations proposed 17 Sustainable Development Goals (SDGs). Among them, tourism, as an emerging comprehensive industry, plays an essential role in the realization of each SDG. According to the data released by the World Travel and Tourism Council (WTTC) in 2019, as a major driving force of global economic growth, tourism contributes to sustainable economic growth by creating one-tenth of the world's jobs, providing adequate employment opportunities and quality employment environments for members of society. In addition, the sustainable consumption and production mode adopted by the tourism industry, such as transforming the resource utilization mode of social and economic development and improving resource utilization efficiency, can accelerate the process of global transformation to sustainable development. The construction of new urbanization requires a green and sustainable development path. As the leading part of the service industry, the role of tourism in the development process of urbanization has become increasingly prominent. The transformation and upgrading of consumption and industrial convergence brought by tourism have enriched the development path of urbanization. [2-4]. However, in recent years, the oversaturation of tourism supply and the excessive use of urban resources have caused damage to urban public space and the ecological environment [5]. There is a coupling relationship among the tourism, urbanization, and ecological environment systems that causes them to promote and restrict each other. Under the premise of ecological sustainability, how to make the most of the factor agglomeration ability and industrial linkage effect of tourism to promote the urbanization process, improve the urban development level, and implement positive interaction and coordinated development among three systems is thus key to regional sustainable development [6].

A coupling coordination relationship refers to the interaction and mutual influence between two or more systems based on a specific connection [7]. The coupling relationship between systems or elements will evolve with time, resulting in the evolution from disharmony to coordination $[8,9]$. The three systems mentioned above have a significant impact on regional economic development, and there is a significant correlation and interaction among them. Existing studies mainly focus on the pairwise relationships between the tourism industry, urbanization, and the ecological environment. There is a limited number of studies that integrate the three systems into the same research framework, and few explore their coupling relationships [10-14]. Moreover, most studies are carried out on provincial or smaller regions rather than nationwide. The tourism industry, urbanization, and the ecological environment are closely related, and the internal development concept is consistent. Tourism promotes urban economic development and improves the level of urbanization. On the contrary, urban construction provides necessary infrastructure and public space for tourism. A good ecological environment provides the basis for sustainable development of the tourism industry and urbanization [8]. Therefore, the research on the coupling relationship between tourism, urbanization, and the ecological environment has 
theoretical and practical significance for promoting high-quality regional tourism development, implementing new urbanization strategy, and improving the ecological environment. From the perspective of the regional economy, due to the differences in resource conditions and economic development level of tourism cities in Eastern, Central, and Western China, the level of urbanization development is unbalanced, which restricts the sustainable development of new urbanization in China. Exploring the coupling development mode and evolution characteristics of the tourism-urbanization-ecological environment system of tourism cities in different regions of China provides a basis for tourism cities in different regions to adjust their tourism development mode according to their actual situation. This can help to promote the development of urbanization and implement the construction of ecological civilization in China.

To address the gaps mentioned above, 35 major tourist cities in Eastern, Central, and Western China were selected as the research samples in this study. By using a comprehensive development index and a coupling coordination degree model, the coordinated development of the tourism-urbanization-ecological environment system was studied for each city, the corresponding temporal and spatial differences were analyzed. The research results indicate the differences and changes in the coordinated development of the system in different regions of China. Subsequently, we discuss our findings and policy implications derived from the findings. Finally, the significance and limitations of the study as well as reflections on future research directions are elaborated.

\section{Literature Review}

\subsection{Tourism Urbanization}

The concept of "tourism urbanization" was first proposed by Australian scholar Mullins in 1991 and specifically refers to a new urban form based on the concept of post-modernist consumption in Western developed countries in the late 20th century. During this period, cities gradually transformed from "production cities" to "consumption cities" [15]. This was characterized by a rise in mass consumption for pleasure. As an important part of hedonistic consumer lifestyles, tourism promoted the shift of population, material, and capital to tourism-dependent areas, its corresponding accumulation, and accelerated the process of local urbanization [16]. Lu points out that with the continuous development of tourism and urbanization, the emergence of tourism urbanization is an inevitable phenomenon [17]. Moreover, tourism urbanization has less impact on resources and ecology than the traditional urbanization development mode. As the basic condition of the tourism industry and urbanization, the ecological environment has an indispensable impact on its development [18]. Therefore, ways to coordinate the relationship between the tourism industry, urbanization, and the ecological environment have become a key focus of scholarly research on tourism urbanization.

Currently, the bulk of research on tourism urbanization mainly revolves around four aspects. The first point concerns definitions and conceptualizations of tourism urbanization. Mullins asserts that tourism urbanization is a distinct urbanization type characterized by establishing or regenerating the consumption of enjoyment and promoting the development of local tourism industries $[1,19]$. Some scholars propose that tourism urbanization is only a stage in the development process of urbanization [20] and as such comprehensively promotes the development of urbanization. Chinese researchers generally regard tourism urbanization as a process of continuous population transfer to and agglomeration in cities driven by a tourism industry. This causes the expansion of cities, the continued improvement in the level of urban modernization, and the accumulation of urbanization elements $[16,21]$. The second aspect concerns the classification of different modes of tourism urbanization. As the literature has shown, systematic classification of the specific characteristics of urbanization provides important cues to determine the development stage of any given urbanization. Through the analysis of relevant case studies, Mullins identifies the key characteristics of tourism urbanization as rapid population growth, coastal distribution, obvious social characteristics of permanent population, and perfect infrastructure [22]. 
Gladstone introduces the concept of "location entropy" and divides tourist cities into two categories: tourism metropolises and leisure tourist cities. Tourism metropolises exhibit differentiated tourism urbanization characteristics [23]. Due to the varied histories and developmental trajectories of different cities, there are significant differences in the development level and modes of tourism. Tourism urbanization also shows other characteristics in the development process, forming various types of tourism urbanization. Wang et al. divide tourism urbanization into two categories, namely connotative and denotative tourism urbanization, based on whether or not tourism development dominates urban population and industrial agglomeration [4]. The third is the driving mechanism of tourism urbanization. According to Martins, there are three long-term driving factors in the process of tourism urbanization: spatial movement of tourists, emergence of infrastructure and services to receive tourists, and leisure and cultural activities to meet the needs of tourists' entertainment [24]. By analyzing the phenomenon of tourism urbanization in different research areas, Chinese scholars have summed up the driving mechanism of tourism urbanization. Wu proposes that the unique national cultural resources, strong promotion of the government, the active participation of villagers, and strong tourist transportation are the main motives of tourism urbanization in Xijiang Qianhu Miao Village [25]. Lu et al. suggest that the main drivers of tourism urbanization in Huangshan Tangkou Town are location, resource endowment, resident participation, and government promotion [26]. By comparing relevant studies, it can be seen that Chinese scholars' research on the driving mechanisms focuses more on the identification of the driving factors of tourism urbanization and less on the mechanism and change process. The fourth is the quantitative research on the internal coupling relationship of the tourism urbanization system. Zhao et al. calculated the coupling degree and coordination degree of the tourism-new urbanization system by using the coupling coordination degree model in 30 provinces of China [1]. Liang comprehensively evaluated the development index of heritage tourism and new urbanization in Shaanxi Province. She also calculated and analyzed the coupling coordination degree between the two subsystems [27]. Wang et al. establish the dynamic coupling coordination model of urbanization and the ecological environment and quantitatively analyzed their coupling process and evolution trend in the Beijing-Tianjin-Hebei region from 1980 to 2011 [28].

\subsection{Coupling Mechanism of the Tourism-Urbanization-Ecological Environment System}

The tourism-urbanization-ecological environment system has extensive connotations and a complex structure. The coupling and coordination relationship between the three subsystems causes them to support and restrict one another. It is of great significance to illuminate the coupling and coordination relationship within the tourism urbanization system and promote the coordinated operation of the three subsystems, which in turn assists their sustainable development.

As an emerging and comprehensive industry, the tourism industry plays a vital role in supporting the development of urbanization. Tourism-related consumption and population aggregation brought by tourism industry development provide the economic power for urban development. At the same time, tourism development also encourages the aggregation of local industries and the continuous improvement of related industries, which provides opportunities for optimizing the industrial structure, forming industrial linkages, and further integrating primary, secondary, and tertiary industries [29]. As a labor-intensive industry, tourism has a high industrial relevance, insofar as it can provide numerous employment opportunities for the rural population, simultaneously directing the flow of rural folk to the city.

The exploitation and utilization of natural resources in the development of tourism will inevitably affect the ecological environment. It is generally agreed that reasonable development and management of tourism resources is conducive to the sustainable utilization of natural and cultural resources and the ecological environment. A good ecological environment will also increase the attraction of tourism resources. On the contrary, excessive and unreasonable development of tourism can cause serious damage to the ecological 
environment, spatial order, and quality of residents' lives in tourism destinations; affect the social and economic development; and further restrict the development of tourism itself $[5,30]$.

The development of urbanization also fosters the development of tourism. The rapid economic growth, the gradual improvement of infrastructure, the increase of residents' income, and the change of behavior mode brought by urbanization provide an opportunity for tourism development [31]. Simultaneously, the development concept of the "production city integration" proposed by the new urbanization project has also provided support for the deep integration of tourism and related industries. The development of urbanization requires a good ecological environment. Attaching importance to ecological environment protection and opting for a green and sustainable new urbanization development path are the basic requirements of current urbanization construction. The development of urbanization provides financial and technical support for ecological environment protection. A good ecological environment is beneficial to improving the quality of urbanization and attracting investment and conversely restricts the quality and scale of urbanization [14].

In summary, the three subsystems of the tourism industry, urbanization, and the ecological environment present a coupling relationship of mutual promotion and mutual restriction (Figure 1). The realization of benign interaction and coordinated development among the three subsystems is an important path to promoting regional sustainable development.

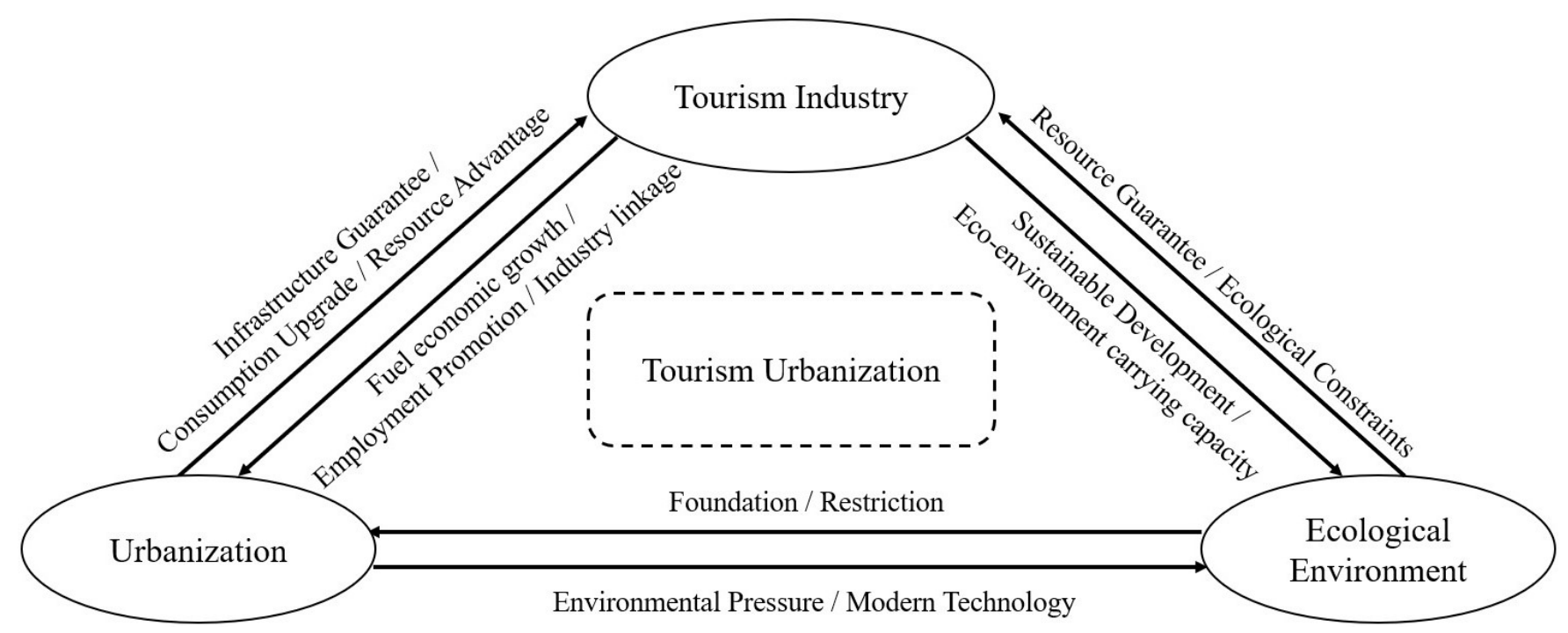

Figure 1. Coupling coordinative interactive mechanism of the tourism-urbanization-ecological environment system.

\section{Methods and Data Sources}

\subsection{Evaluation Index System Construction and Data Sources}

Through the above analysis, it can be gleaned that there is a coupling relationship between the tourism industry, urbanization, and the ecological environment. To evaluate the coupling coordination degree among the three subsystems, an evaluation index system of the tourism-urbanization-ecological environment system was constructed. As there is no unified measurement standard for the tourism urbanization development level, the relevant research results of the current scholars [32-34] were considered to construct a tourism-urbanization-ecological environment system based on the principles of comprehensiveness, scientificity, and comparability. The system contains 26 specific indicators (Table 1). The tourism industry subsystem contains eight indicators, which mainly reflect the market scale, economic benefits, and factor structure of the tourism industry. The urbanization subsystem contains nine indexes, which mainly reflect the urbanization level of the economy, population, and society. The ecological environment subsystem contains nine indicators, which mainly reflect the pressure, state, and response of the ecological 
environment to the development of tourism and urbanization. In the process of standardization, the positive and negative index data are processed according to the formula. In order to avoid meaningless assignment, the standardized value is processed by adding 0.0001. In order to prevent subjective factors from affecting the calculation results of index weight, a more objective entropy method for index weight was used in this study.

Table 1. Evaluation index system of the tourism-urbanization-ecological environment system.

\begin{tabular}{|c|c|c|c|}
\hline Subsystem & Evaluation Index & Nature & Weight \\
\hline \multirow{8}{*}{ Tourism industry } & Number of inbound tourists $(10,000$ people $)$ & + & 0.1630 \\
\hline & Number of domestic tourists ( 10,000 people $)$ & + & 0.1159 \\
\hline & Foreign exchange earnings from tourism (USD 10,000) & + & 0.1811 \\
\hline & Domestic tourism revenue $(100,000,000$ yuan) & + & 0.1092 \\
\hline & Total tourism revenue $(100,000,000$ yuan $)$ & + & 0.1084 \\
\hline & Tourism income as a percentage of GDP (\%) & + & 0.1403 \\
\hline & Number of star hotels & + & 0.1147 \\
\hline & Number of travel agencies & + & 0.0673 \\
\hline \multirow{9}{*}{ Urbanization } & Urban per-capita disposable income (yuan/person) & + & 0.1062 \\
\hline & Urban Road area per capita $\left(\mathrm{m}^{2} /\right.$ person $)$ & + & 0.1121 \\
\hline & Urban end-of-year registered unemployment rate (\%) & - & 0.0838 \\
\hline & Number of public vehicles in operation & + & 0.3098 \\
\hline & GDP per capita (yuan/person) & + & 0.1152 \\
\hline & Secondary industry as a percentage of GDP (\%) & + & 0.0528 \\
\hline & Tertiary industry as a percentage of GDP (\%) & + & 0.1043 \\
\hline & Proportion of employed population in secondary industry (\%) & + & 0.0592 \\
\hline & Proportion of employed population in tertiary industry (\%) & + & 0.0566 \\
\hline \multirow{9}{*}{ Ecological environment } & Industrial sulfur dioxide emissions (10,000 tons) & - & 0.0517 \\
\hline & Industrial soot emissions $(10,000$ tons $)$ & - & 0.0100 \\
\hline & Industrial wastewater discharge ( 10,000 tons $)$ & - & 0.0841 \\
\hline & Green coverage rate in built-up areas (\%) & + & 0.1372 \\
\hline & Per capita park green area $\left(\mathrm{hm}^{2} /\right.$ person $)$ & + & 0.2396 \\
\hline & Days of air quality at level 2 or higher & + & 0.2031 \\
\hline & Comprehensive utilization rate of industrial solid waste (\%) & + & 0.1375 \\
\hline & Centralized treatment rate of urban sewage $(\%)$ & + & 0.0693 \\
\hline & Pollution-free treatment rate of domestic garbage $(\%)$ & + & 0.0675 \\
\hline
\end{tabular}

Major tourist cities are those with strong tourism function. Categorization of tourist cities established by relevant scholars [35] was adopted in this study, and the level of tourism development in Chinese tourist cities was evaluated according to two dimensions, namely urban functional scale and functional status. The functional scale dimension is measured by the total number of urban tourism receptions, and the functional status dimension is measured by the proportion of total tourism income to GDP. Combined with the principle of data availability, 35 cities were selected as major tourist cities in China.

In 2009, the National Tourism Administration launched "China's Ecotourism Year", which further strengthened the publicity of eco-tourism and environment-friendly tourism, advocated the implementation of resource-saving tourism management, and turned the tourism industry into a more green and sustainable industry. In 2012, the 18th Communist Party of China (CPC) National Congress proposed "new urbanization", advocated the exploration of a diversified new urbanization development path, and provided new potential space for the development of tourism. In 2015, the Fifth Plenary Session of the 18th CPC Central Committee formally incorporated "beautiful China" into the 13th Five-Year Plan, which further attached importance to the construction of ecological civilization and promoted the rapid development of the tourism industry. In 2018, the comprehensive pilot task of national new urbanization achieved phased results. Therefore, data from 2009 to 2018 were selected for this study, and a comparative analysis was conducted on the crosssectional data of 2009, 2012, 2015, and 2018. The index data used in this study were from the China Tourism Statistical Yearbook, China Statistical Yearbook, China Urban Statistical 
Yearbook, and the statistical database of China Economic Information Network and the statistical bulletin of cities. Some missing values are supplemented by interpolation.

\subsection{Calculation of Comprehensive Development Index}

The entropy method mainly uses observation information to objectively determine the weight of the evaluation indices. This method can overcome the shortcomings of a subjective weighting approach, such as large influence by subjective experience and weak persuasion, and therefore reduce the error caused by subjectivity. At present, the entropy method is widely used in the field of social and economic research [36,37]. The entropy value depends on the amount of observation information. That is, the greater the amount of information, the higher the degree of data dispersion, and the higher the entropy valueand vice versa. As this study involved panel data for research, the improved entropy method was used to determine the index weight instead of the traditional entropy method, which is only suitable for cross-sectional data. Finally, the comprehensive development index was used to represent the development level of the subsystem. The main steps are as follows.

(1). Calculation of efficacy coefficient. The original data were standardized to eliminate the impact of different dimensions on various indicators. The calculation formula is as follows:

$$
X_{\sigma i j}=\left\{\begin{array}{l}
\frac{x_{\sigma i j}-M I N_{j}}{M A X_{j}-M I N_{j}}+0.0001 \text { (positive index) } \\
\frac{M A X_{j}-x_{\sigma i j}}{M A X_{j}-M I N_{j}}+0.0001 \text { (negative index) }
\end{array}\right.
$$

(2). Conversion index proportion.

$$
p_{\sigma i j}=\frac{X_{\sigma i j}}{\sum_{\sigma=1}^{k} \sum_{i=1}^{m} X_{\sigma i j}}
$$

(3). Calculation of index entropy.

$$
e_{j}=-\frac{1}{\ln (m \times k)} \sum_{\sigma=1}^{k} \sum_{i=1}^{m} p_{\sigma i j} \ln p_{\sigma i j}
$$

(4). Calculation of criteria overlap degree.

$$
\beta_{j}=1-e_{j}
$$

(5). Determination of index weight.

$$
w_{j}=\frac{\beta_{j}}{\sum_{j=1}^{n} \beta_{j}}
$$

In Formula (1), $X_{\sigma i j}$ represents the standardized value of the index $j$ for the year $\sigma$ of the city $i . x_{\sigma i j}$ represents the original value of the index $j$ for the year $\sigma$ of the city $i . M A X_{j}$ is the maximum value of the index $j . M I N_{j}$ is the minimum value of the index $j . \sigma=1,2 \ldots$ $\ldots$ k represents the year. $i=1,2 \ldots \ldots$ m represents the city. $j=1,2,3 \ldots \ldots$ m represents the index.

Finally, the comprehensive development index of each subsystem is calculated. The calculation formula is as follows:

$$
U_{i}=\sum_{j=1}^{n} w_{i j} X_{\sigma i j}, \sum_{j=1}^{n} w_{i j}=1
$$


In Formula (6), $U_{i}(i=1,2,3)$ represents the comprehensive development index of the tourism industry subsystem, urbanization subsystem, or ecological environment subsystem in each year. Since panel data were used in this study, $w_{i j}$ is the average weight of 10 years from 2009 to 2018.

\subsection{Coupling Coordination Model}

The coupling degree is an important indicator to reflect the relationship and intensity between different systems or elements. This study explored the correlation degree between different indicators of the tourism industry, urbanization, and the ecological environment in Chinese tourist cities through the coupling degree model. The calculation formula is as follows.

$$
C=3 \times\left[\frac{U_{1} \times U_{2} \times U_{3}}{\left(U_{1}+U_{2}+U_{3}\right)^{3}}\right]^{\frac{1}{3}}
$$

In Formula (7), $C$ is the coupling degree. $C \in(0,1]$. A larger value of $C$ indicates a higher coupling degree between the systems. When $C=1$, the coupling degree of the three subsystems is the largest; that is, the tourism-urbanization-ecological environment system is in the high-level coupling stage and is likely to reflect orderly and benign development. When $C$ approaches 0 , however, the tourism-urbanization-ecological environment system is considered to be in the coupling detuning state. The coupling degree can be divided into 3 types (Table 2 ).

Table 2. Classification of coupling degree.

\begin{tabular}{cc}
\hline$C$ Value Interval & Coupling Type \\
\hline$(0,0.3]$ & Low \\
$(0.3,0.5]$ & Antagonistic \\
$(0.5,0.8]$ & Run-in \\
$(0.8,1]$ & High \\
\hline
\end{tabular}

Although the coupling degree can effectively calculate the coupling strength of the system, it cannot reflect the coordination degree of the subsystems. Therefore, it is necessary to use the coupling coordination model to evaluate the coordination degree of the interactive development of tourism, urbanization, and the ecological environment of a city. The calculation formula of the coupling coordination degree is as follows.

$$
\begin{gathered}
D=\sqrt{C \times T} \\
T=\alpha U_{1}+\beta U_{2}+\gamma U_{3}
\end{gathered}
$$

In Formula (8), $D$ is the coupling coordination degree, $T$ is the comprehensive coordination index of the three systems of tourism, urbanization, and the ecological environment. $\alpha, \beta, \gamma$ represent the weights of the tourism industry, urbanization, and the ecological environment in the whole system, respectively. This study used a combination of expert scoring and comprehensive investigation to determine the index weights. By comprehensive measurement, $\alpha=0.25, \beta=0.40, \gamma=0.35$ were finally determined. Drawing on previous research results, the coupling coordination degree was divided into 10 levels and 3 types (Table 3 ). 
Table 3. Classification of coupling coordination degree.

\begin{tabular}{ccc}
\hline $\boldsymbol{D}$ Value Interval & Coupling Coordination Level & Coupling Coordination Type \\
\hline$(0,0.1]$ & Extreme maladjustment & \\
$(0.1,0.2]$ & Serious maladjustment & Coordinated recession \\
$(0.2,0.3]$ & Moderate maladjustment & \\
$(0.3,0.4]$ & Mild maladjustment & \\
$(0.4,0.5]$ & On the verge of maladjustment & Coordinated transition \\
$(0.5,0.6]$ & Grudging coordination & \\
$(0.6,0.7]$ & Primary coordination & \\
$(0.7,0.8]$ & Intermediate coordination & Coordinated development \\
$(0.8,0.9]$ & Good coordination & \\
$(0.9,1]$ & High-quality coordination & \\
\hline
\end{tabular}

\section{Results}

\subsection{Analysis of Comprehensive Development Index}

According to the established evaluation index system, the comprehensive development indexes of the three subsystems of 35 major tourist cities in China from 2009 to 2018 were calculated. Based on geographical regions, the 35 cities were further divided into three regions: eastern, central, and western.

The comprehensive development index of the tourism industry subsystem and urbanization subsystem of major tourist cities in China shows a steady upward trend, indicating that the tourism industry and urbanization level of China's major tourist cities have been rapidly developed and improved from 2009 to 2018. However, the overall development level is still low from a numerical point of view. The ecological environment subsystem has no significant growth trend. By comparing the scores of the three subsystems, the average scores of the ecological environment subsystem, the urbanization subsystem, and the tourism subsystem were ranked from high to low. Among them, the comprehensive development index of the ecological environment is significantly higher than that of the other two systems. The continuous optimization of the ecological environment supports the development of the tourism industry and the increment of the urbanization level (Table 4).

Based on the analysis of the comprehensive development index of cities in each region, the average development levels of the tourism industry and urbanization in eastern cities are significantly higher than those in central and western cities. The comprehensive development indexes of the tourism industries in Beijing, Tianjin, Shanghai, Nanjing, Suzhou and Hangzhou are all greater than 0.1. Furthermore, the comprehensive development indexes of the tourism industries in Beijing, Shanghai, Guangzhou and Shenzhen are significantly higher than the average development level of the region. The corresponding comprehensive development indexes of urbanization in these cities are also high. These cities are all large or medium-sized cities with developed economies, rich tourism resources, perfect infrastructure, and developed transportation [35], which suggests that the tourism development of the city is significantly affected by urban resources. The rapid development of urbanization provides impetus and support for tourism development. The tourism industries in the central and western regions are at a low level compared with those in the eastern region. Nonetheless, the comprehensive development indexes of the tourism industries in Wuhan, Chongqing, Lijiang, and Huangshan are relatively advanced. Of these, Wuhan and Chongqing are of the same type and possess the highest level of comprehensive development indexes of urbanization in the central region, suggesting that the urbanization development of the city promotes the development of the tourism industry. In comparison, Lijiang and Huangshan are both natural resource-based cities with ecological environments in a significantly better condition than that of other cities, which bolsters tourism development and an ecological basis for the urbanization development. 
Table 4. Comprehensive development indexes of the tourism industry, urbanization, and the ecological environment of major tourist cities in China.

\begin{tabular}{|c|c|c|c|c|c|c|c|c|c|c|c|c|c|}
\hline \multirow{2}{*}{ Region } & \multirow{2}{*}{ City } & \multicolumn{4}{|c|}{ Tourism Industry } & \multicolumn{4}{|c|}{ Urbanization } & \multicolumn{4}{|c|}{ Ecological Environment } \\
\hline & & 2009 & 2012 & 2015 & 2018 & 2009 & 2012 & 2015 & 2018 & 2009 & 2012 & 2015 & 2018 \\
\hline \multirow{14}{*}{ Eastern } & Beijing & 0.411 & 0.501 & 0.520 & 0.577 & 0.487 & 0.534 & 0.588 & 0.646 & 0.612 & 0.649 & 0.587 & 0.610 \\
\hline & Tianjin & 0.123 & 0.206 & 0.290 & 0.278 & 0.299 & 0.356 & 0.402 & 0.435 & 0.531 & 0.575 & 0.497 & 0.494 \\
\hline & Dalian & 0.093 & 0.107 & 0.110 & 0.134 & 0.278 & 0.324 & 0.354 & 0.391 & 0.644 & 0.649 & 0.548 & 0.627 \\
\hline & Qingdao & 0.091 & 0.107 & 0.131 & 0.169 & 0.299 & 0.344 & 0.386 & 0.431 & 0.687 & 0.700 & 0.653 & 0.694 \\
\hline & Shanghai & 0.385 & 0.509 & 0.509 & 0.642 & 0.355 & 0.392 & 0.439 & 0.509 & 0.592 & 0.616 & 0.481 & 0.550 \\
\hline & Nanjing & 0.115 & 0.156 & 0.144 & 0.191 & 0.324 & 0.397 & 0.495 & 0.538 & 0.576 & 0.612 & 0.563 & 0.615 \\
\hline & Suzhou & 0.123 & 0.180 & 0.193 & 0.245 & 0.338 & 0.409 & 0.474 & 0.538 & 0.646 & 0.613 & 0.559 & 0.588 \\
\hline & Hangzhou & 0.166 & 0.210 & 0.275 & 0.379 & 0.322 & 0.401 & 0.462 & 0.547 & 0.615 & 0.663 & 0.578 & 0.614 \\
\hline & Xiamen & 0.071 & 0.113 & 0.154 & 0.246 & 0.265 & 0.332 & 0.366 & 0.410 & 0.659 & 0.661 & 0.665 & 0.706 \\
\hline & Guangzhou & 0.258 & 0.347 & 0.410 & 0.505 & 0.379 & 0.443 & 0.486 & 0.560 & 0.616 & 0.664 & 0.687 & 0.687 \\
\hline & Shenzhen & 0.233 & 0.329 & 0.370 & 0.392 & 0.592 & 0.684 & 0.721 & 0.824 & 0.730 & 0.734 & 0.741 & 0.677 \\
\hline & Sanya & 0.051 & 0.060 & 0.066 & 0.097 & 0.199 & 0.229 & 0.274 & 0.316 & 0.791 & 0.801 & 0.743 & 0.710 \\
\hline & Qinhuangdao & 0.025 & 0.034 & 0.049 & 0.085 & 0.208 & 0.234 & 0.240 & 0.289 & 0.688 & 0.731 & 0.672 & 0.678 \\
\hline & Ningbo & 0.088 & 0.114 & 0.134 & 0.151 & 0.262 & 0.341 & 0.398 & 0.453 & 0.591 & 0.606 & 0.567 & 0.622 \\
\hline \multirow{11}{*}{ Central } & Harbin & 0.044 & 0.054 & 0.075 & 0.102 & 0.168 & 0.236 & 0.259 & 0.308 & 0.517 & 0.593 & 0.518 & 0.567 \\
\hline & Zhengzhou & 0.055 & 0.070 & 0.086 & 0.109 & 0.241 & 0.287 & 0.361 & 0.402 & 0.527 & 0.514 & 0.381 & 0.513 \\
\hline & Wuhan & 0.071 & 0.144 & 0.207 & 0.282 & 0.262 & 0.322 & 0.375 & 0.463 & 0.537 & 0.591 & 0.518 & 0.554 \\
\hline & Zhangjiajie & 0.048 & 0.082 & 0.117 & 0.204 & 0.167 & 0.182 & 0.186 & 0.245 & 0.539 & 0.629 & 0.607 & 0.652 \\
\hline & Changsha & 0.055 & 0.094 & 0.130 & 0.151 & 0.242 & 0.284 & 0.368 & 0.441 & 0.603 & 0.605 & 0.557 & 0.598 \\
\hline & Huangshan & 0.066 & 0.094 & 0.109 & 0.136 & 0.127 & 0.176 & 0.208 & 0.257 & 0.676 & 0.710 & 0.717 & 0.754 \\
\hline & Guilin & 0.048 & 0.076 & 0.103 & 0.195 & 0.122 & 0.151 & 0.175 & 0.222 & 0.551 & 0.630 & 0.606 & 0.679 \\
\hline & Changchun & 0.032 & 0.049 & 0.079 & 0.123 & 0.209 & 0.260 & 0.290 & 0.323 & 0.659 & 0.661 & 0.609 & 0.666 \\
\hline & Hohhot & 0.017 & 0.026 & 0.041 & 0.069 & 0.237 & 0.290 & 0.332 & 0.328 & 0.661 & 0.613 & 0.598 & 0.596 \\
\hline & Jinzhong & 0.021 & 0.034 & 0.063 & 0.105 & 0.186 & 0.216 & 0.240 & 0.276 & 0.582 & 0.633 & 0.655 & 0.580 \\
\hline & Nanchang & 0.016 & 0.027 & 0.051 & 0.118 & 0.181 & 0.263 & 0.267 & 0.319 & 0.620 & 0.658 & 0.643 & 0.668 \\
\hline \multirow{10}{*}{ Western } & Xi'an & 0.059 & 0.103 & 0.138 & 0.238 & 0.222 & 0.293 & 0.324 & 0.372 & 0.526 & 0.614 & 0.577 & 0.463 \\
\hline & Chongqing & 0.126 & 0.232 & 0.293 & 0.418 & 0.187 & 0.258 & 0.280 & 0.327 & 0.480 & 0.667 & 0.613 & 0.631 \\
\hline & Chengdu & 0.071 & 0.130 & 0.199 & 0.308 & 0.270 & 0.320 & 0.356 & 0.425 & 0.606 & 0.640 & 0.586 & 0.578 \\
\hline & Kunming & 0.050 & 0.067 & 0.091 & 0.185 & 0.246 & 0.280 & 0.317 & 0.369 & 0.647 & 0.599 & 0.576 & 0.599 \\
\hline & Lijiang & 0.080 & 0.106 & 0.161 & 0.249 & 0.148 & 0.188 & 0.196 & 0.238 & 0.630 & 0.730 & 0.738 & 0.834 \\
\hline & Zunyi & 0.012 & 0.029 & 0.045 & 0.116 & 0.106 & 0.120 & 0.158 & 0.224 & 0.526 & 0.597 & 0.648 & 0.772 \\
\hline & Yinchuan & 0.004 & 0.007 & 0.011 & 0.017 & 0.229 & 0.258 & 0.282 & 0.321 & 0.683 & 0.603 & 0.633 & 0.576 \\
\hline & Jiuquan & 0.011 & 0.017 & 0.029 & 0.051 & 0.142 & 0.185 & 0.231 & 0.252 & 0.561 & 0.613 & 0.625 & 0.583 \\
\hline & Xining & 0.016 & 0.018 & 0.024 & 0.035 & 0.148 & 0.204 & 0.265 & 0.284 & 0.495 & 0.582 & 0.610 & 0.569 \\
\hline & Urumqi & 0.024 & 0.039 & 0.033 & 0.055 & 0.228 & 0.259 & 0.319 & 0.355 & 0.418 & 0.544 & 0.527 & 0.602 \\
\hline
\end{tabular}

\subsection{Analysis of Coupling Degree}

In order to display the change characteristics of system coupling degree intuitively in major tourist cities in China in different periods, ArcGIS analysis software was used in this study to draw the spatial distribution map of the system coupling degree in 2009, 2012, 2015, and 2018 (Figure 2). According to the classification standard of coupling degrees, 35 major tourist cities were divided into four types. 

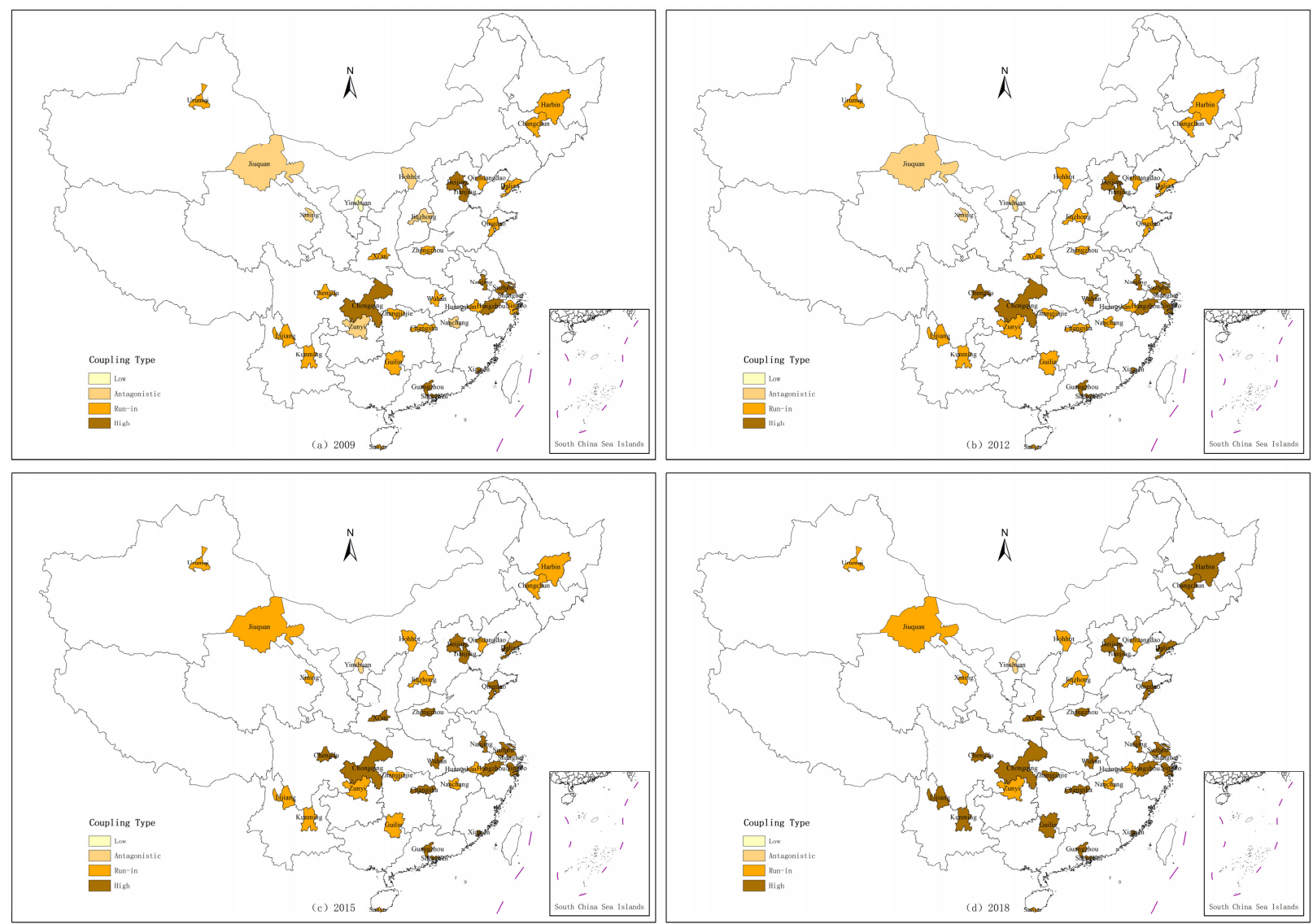

Figure 2. Spatial variation of coupling degree of the tourism-urbanization-ecological environment system in major tourist cities in China.

Overall, the system coupling degree in China's major tourist cities has shown a significant upward trend in the past decade. Most cities have achieved a high level of coupling. In 2009, there were nine tourist cities in the high-level coupling stage, eight of which were eastern tourist cities, with Chongqing being the only western exception. There were 19 tourist cities in the run-in stage, most of which were central and eastern tourist cities. There were six tourist cities in the antagonistic stage, all of which were central and western tourist cities. In 2009, only Yinchuan was in the low-level coupling stage amongst 35 tourist cities in China. Through the analysis, we can see that the coupling degree of the tourism city system in the early stage of China's central and western regions was at a low level, which indicates that the cities' economic development levels, traffic locations, tourism resources, urban infrastructure, and other factors had an impact on the coupling strength. In the early stage, the extensive urbanization development mode dominated by industrial development was mostly adopted in various regions, and the interaction effect with tourism and the ecological environment was not obvious. In 2012, the 18th CPC National Congress proposed the new-type urbanization and incorporated "ecological civilization" into the overall layout of "five-in-one", which significantly improved the coupling effect of the three subsystems. The overall layout of five-in-one refers to the comprehensive promotion of economic, political, cultural, social, and ecological civilization constructions. From 2012 to 2015, the system coupling degree in the central and western regions increased gradually, exceeding those in the eastern region. As of 2018, 24 major tourist cities reached a high level of coupling degree. The three subsystems reached a benign resonance coupling state. The proportion of cities with a high coupling degree reflects a law of decreasing in the east, central, and western regions. The urbanization development of the central and western regions started relatively late, and the economic level was undeveloped. In the early stage, the traditional urbanization development mode dominated by industrialization was mostly 
adopted. The urban tourism infrastructure was not complete, and tourism played a small role in urbanization. Moreover, the urbanization led by industrialization has caused a negative impact on the ecological environment, which leads to weaker interactions between subsystems and a lower degree of system coupling. Noticeable spatial differences can be observed in the coupling degree of the tourism-urbanization-ecological environment system in Chinese tourist cities, which reflects the positive effect of the urbanization level on the coupling strength of the system.

\subsection{Analysis of Coupling Coordination Degree}

In order to further explore the coordination degree of the internal subsystems of the tourism-urbanization-ecological environment system in major tourist cities in China and to analyze the spatiotemporal differences, cross-sectional data for the four years of 2009, 2012,2015 , and 2018 were selected for this study, and a spatial visualization analysis was performed.

The results in Figure 3 show that in 2009, the system coupling coordination degrees of the 35 tourist cities were relatively low. Four cities were in the stage of coordinated development (primary coordination and intermediate coordination), 22 cities were in the stage of coordinated transition (on the verge of imbalance and barely coordinated), and the remaining nine cities were in the stage of coordinated recession (mild imbalance). In the early stage, the development of tourism industries in Chinese cities was relatively slow. People spent more on daily life expenditure and less on tourism and leisure. In addition, the traditional urbanization development mode was mostly industrial development, which failed to provide the sufficient infrastructure required by the tourism industry. In the process of developing tourism and strengthening urbanization, less emphasis was placed on ecological protection, which brought pressure on the ecological environment and led to poor coupling and coordination within the system. From 2009 to 2015, the coupling coordination degree of tourist cities had further improved. As of 2015, the nine cities in the early stage of coordination decline had all risen to the "coordinated transition" stage, mainly due to the rapid tourism industry development and the acceleration of urbanization. In 2018, 16 cities rose to the stage of coordinated development, which was four times the number recorded in 2009. In recent years, the state has vigorously advocated the construction of ecological civilization. Local governments have paid increasing attention to the ecological environment protection while vigorously developing tourism, thus strengthening the positive interaction between tourism and the ecological environment. At the same time, local governments have actively responded to the requirements of new urbanization, promoting the urbanization development through tourism and accelerating the integration and development of the tourism industry, urbanization, and the ecological environment, and in so doing improving the coupling and coordination degree of the tourism-urbanization-ecological environment system. In terms of spatial distribution, there is a significant difference in the level of urban coupling coordination amongst the eastern, central, and western regions. The urban coupling coordination in the eastern region is significantly higher than that in the central and western regions, which is similar to the spatial variation characteristics of the coupling degree. From the above analysis, it can be noted that although the coupling coordination degree within the subsystems is increasing year by year, it is still at a low level. It is concluded that the overall level of tourism development and urbanization in each city lags behind that of the ecological environment, which is the main reason for the low overall level of system coupling and coordination. 

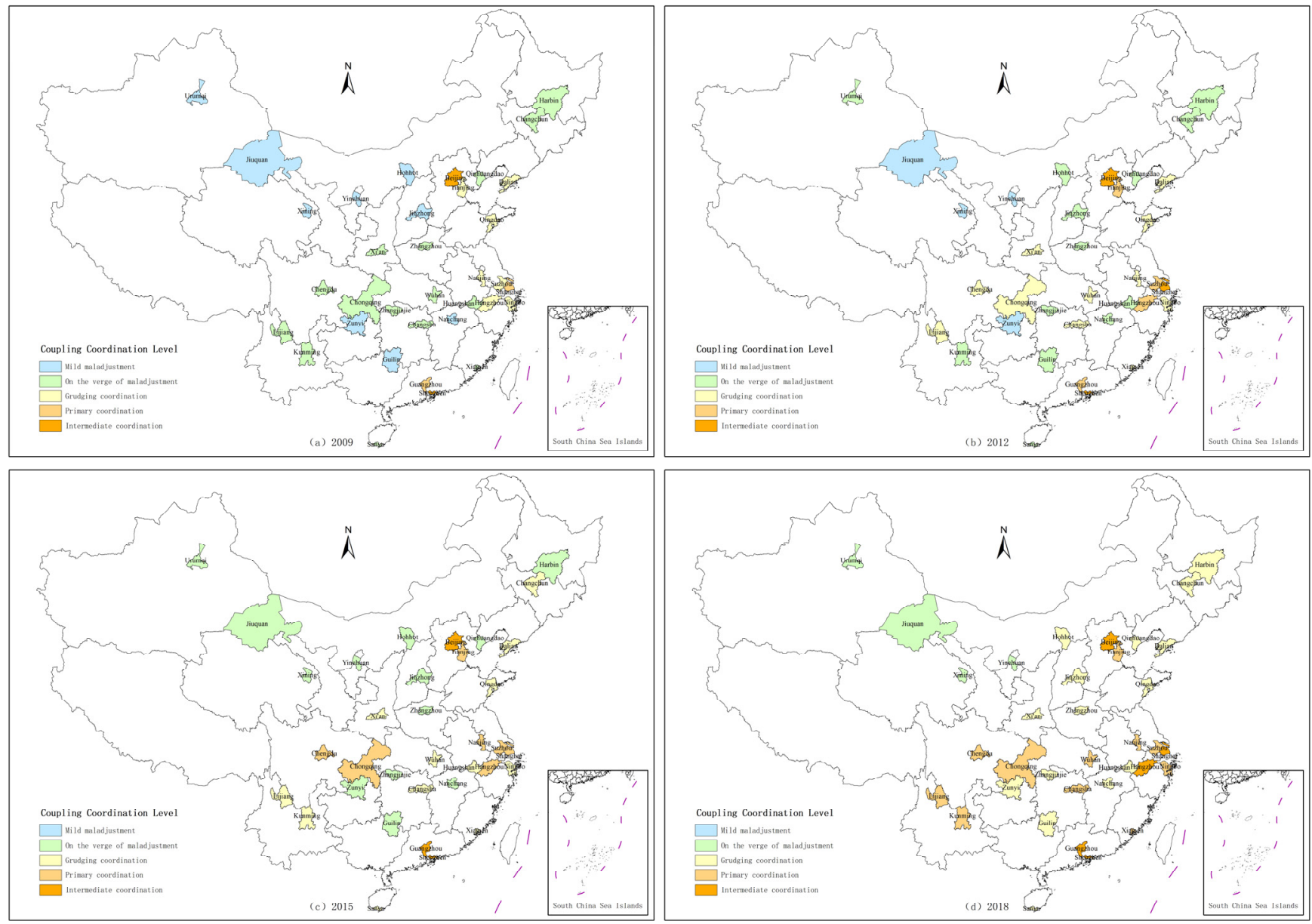

Figure 3. Spatial variation of coupling coordination degree of the tourism-urbanization-ecological environment system in major tourist cities in China.

\section{Discussion}

Due to the need for harmonious development between human beings and nature, sustainable development has become a matter of concern in countries across the world. In recent years, with the acceleration of tourism development, the interaction between tourism activities and the ecological environment has become increasingly complex. Many countries are actively exploring new development models for urbanization. China has clearly proposed a green and sustainable urbanization path, relying on tourism to vigorously promote the new urbanization development. Tourism is also closely linked to the urban ecological environment. There is a dynamic relationship among the tourism industry, urbanization, and the ecological environment, which causes these three factors to promote and restrict each other. Vigorously developing the tourism industry, promoting the construction of a new type of urbanization, and building an ecologically civilized society are important means to promoting coordinated regional development and sustainable economic growth. An evaluation index system of the tourism-urbanization-ecological environment system was constructed in this study, and the evolution characteristics of the coupling of the abovementioned system were analyzed for 35 major tourist cities in China from 2009 to 2018 by utilizing the comprehensive development index and coupling coordination model.

The results show that the overall development level of the tourism industry and urbanization in China's major tourist cities shows an increasing trend. The average development level and urbanization level of the tourism industry and urbanization in eastern cities are significantly higher than those in central and western cities, and the comprehensive development index of large and medium-sized cities is higher. From 2009 to 2018, the cou- 
pling degree of the tourism-urbanization-ecological environment system in China's major tourist cities showed a significant upward trend. Most cities have reached a high level of coupling stage. The overall system coupling coordination degree of China's major tourist cities from 2009 to 2018 showed an upward trend of "coordinated recession-coordinated transition-coordinated development", but the overall coordination level is still low, as most cities are still in the stage of coordinated transition. The coupling coordination degree of eastern cities is significantly higher than that of central and western regions.

The results further verify the existing research results. Relevant research shows that the level of urbanization will have a great impact on the development of the tourism industry [38]. Large and medium-sized cities with a high urbanization level can provide the infrastructure required for the development of tourism. At the same time, the rapid development of urbanization can also provide high-quality professional support for tourism [29]. The results of this study show that the comprehensive development indexes of the tourism industry in eastern cities are significantly higher than those in the central and western cities. The comprehensive development indexes of the tourism industry in Wuhan and Chongqing, which have higher urbanization level in the central and western regions, are also significantly higher than other cities in the same region. Such findings thus verify the existing research results. There is an interactive relationship between urbanization and tourism $[39,40]$. Urbanization will play a structural driving role in the development of tourism [41] and promote the development of accommodation, catering, shopping, and entertainment infrastructures as well as other tourism-related service industries.

Further analysis reveals that the coupling degree and coupling coordination degree of the tourism-urbanization-ecological environment system in China's major tourist cities increase yearly. In particular, since the Chinese government introduced the new urbanization path in 2012, the construction of an ecological civilization in the process of urbanization has been emphasized, closely integrating the development of tourism with the protection of the ecological environment. Thus, the coupling coordination degree of the tourismurbanization-ecological environment system has been further improved. The study shows that the coupling degree and coordination degree of the central and western cities are significantly lagging behind those of the eastern cities, and the internal heterogeneity is higher than that of the eastern cities. During the early stages of urbanization development in the central and western regions, industrial development was adopted, sidelining ecological protection in the process. The level of urbanization development was low. Instead, central and western cities paid attention to the development of leisure tourism based on natural tourism resources. The above factors lead to the weak relationship between subsystems. Existing research shows that a strong coupling relationship among the tourism industry, urbanization, and the ecological environment can be established. However, only when one or two sides of the tourism industry, urbanization, and the ecological environment develop to a certain level can they drive the remaining subsystems. In addition, the tourism industry, urbanization, and the ecological environment are key to the development of mutual adaptation and mutual coordination in order to achieve the mutual promotion effect [18].

According to the spatiotemporal evolution characteristics of the coupling relationship in the tourism-urbanization-ecological environment systems in China's major tourist cities, a number of practical recommendations can be formulated.

Firstly, governments should depart from the traditional urbanization development model led by heavy industry and instead support emerging industries, such as the tourism industry, in the development of urbanization. As a modern service sector, tourism is labor-intensive and has strong factor agglomeration capabilities, which can create many employment opportunities, attract rural laborers to employment in cities, promote the development of the regional economy, and improve the life quality of residents in destinations. Therefore, relevant regions should take the promotion of tourism development as an important idea for the construction of new urbanization, pay attention to the embedding of tourism or leisure functions in the process of urban construction, and improve the efficiency of urban space utilization. In the process of development, attention ought to be given to 
the impact of tourism and urbanization on the ecological environment, so as to effectively balance the relationship between the three.

Secondly, the level of tourism and urbanization in the eastern region is relatively high, and more attention is dedicated to environmental governance and ecological protection in the development process. Cities in the eastern region are an ideal exemplars for the central and western cities; the latter should seek to change the traditional tourism development mode, actively promote the transformation and upgrading of tourism development mode, strengthen the ecological protection and resource utilization in the development process of the tourism industry, and strive to enhance the competitiveness of their tourism brand. Such efforts can help enhance the agglomeration capacity of the elements of regional tourism and promote the development process of new urbanization. All in all, cities in China ought to narrow the gap of industrial development levels between the eastern, central, and western regions and promote the high-quality and sustainable development of China's tourism urbanization level. Each region should formulate targeted tourism urbanization development strategies that meet the actual conditions of the region and adjust the development mode of tourism and new urbanization according to local conditions. Finally, the new urbanization is human-centered urbanization. The essence is to shift from focusing on the expansion and promotion of urban material to satisfaction of people's needs and all-round development. Tourism can not only promote the ecological construction of new urbanization but also effectively promote in situ urbanization, further promote the integration of urban and rural industries, and enable destination residents to diversify their income sources and professional identities in the process of urbanization. We can take characteristic towns, agricultural parks, and tourism greenways as the starting point to accelerate the transformation of development mode and efficiently promote new urbanization.

\section{Conclusions}

The tourism industry, urbanization, and the ecological environment all have important impacts on regional economic development, and there are significant correlations and interactions among them. Few studies have incorporated the systems of the tourism industry, urbanization, and the ecological environment into the same research framework and explored their coupling relationships. There are also relatively few studies that analyzed the coupling development of the tourism urbanization system in different cities in China from a spatiotemporal perspective. Based on the data of 35 major tourist cities in China from 2009 to 2018, this study evaluated the coupling coordination and dynamic relationships within the tourism-urbanization-ecological environment system. It compared the development level of tourism urbanization and the coupling degree and coordination degree of the abovementioned system in the major tourist cities in Eastern, Central, and Western China. The results further deepen the understanding of the coupling development mode and spatiotemporal evolution law of the composite system and enrich the dimension and depth of tourism coupling research. This study also provides a basis for tourism cities in various regions of China to formulate new urbanization development measures, accelerate tourism supply-side reforms, and implement ecological civilization construction based on their own resource conditions and development levels. This may help to further equalize the development level between the cities as well as improve the overall coordination between the tourism industry, urbanization, and the ecological environment in China.

However, this study is not without limitations. Due to the difficulty of data acquisition and the complexity of the system, the selection of evaluation indexes will differ amongst different scholars. This will affect the research results to a certain extent and lead to certain limitations in this study. In addition, there is still a big gap between China's current urbanization development level and that of Western countries. The results of this paper show that the coupling degree and coordination degree of the tourism-urbanization-ecological environment system of 35 tourism cities in China have an upward trend. However, the existing literature shows that in some Western and Asian cities, excessive tourism develop- 
ment and tourism supply may exceed urban space carrying capacity, which then brings many negative effects to the city and damages the ecological sustainability of the tourism industry $[5,42,43]$. As such, on the basis of integrating multidisciplinary research methods and ideas, future studies may probe the coupling and coordination mechanism within the three subsystems of the tourism industry, urbanization, and the ecological environment; identify the influencing factors leading to the differences and changes in the internal coordination of the system; explore how to utilize tourism to promote urbanization within the scope of urban and ecological environment carrying capacity; and balance the relationship between ecological sustainability of tourism and social sustainability.

Author Contributions: Conceptualization, X.X. and C.Z.; data curation, H.S. and F.C.; formal analysis, X.X. and H.S.; funding acquisition, X.X. and C.Z.; investigation, F.C.; methodology, H.S.; original draft, X.X. and H.S.; review and editing, J.G. All authors have read and agreed to the published version of the manuscript.

Funding: This work was supported by the Key Laboratory for Sustainable Development of Xinjiang's Historical and Cultural Tourism in Xinjiang, grant number 2020D04105; the University Scientific Research Plan Project of Humanities and Social Sciences in Xinjiang, grant number XJEDU2019SY006; and the Project of Decision-Making Research and Consulting by the expert advisory team in Xinjiang, grant number JZ202002001.

Institutional Review Board Statement: Not applicable.

Informed Consent Statement: Not applicable.

Data Availability Statement: Data is contained within the article.

Conflicts of Interest: The authors declare there are no conflict of interest.

\section{References}

1. Zhao, L.; Pan, T.T.; Fang, C.; Lin, S. Tourism industry and new urbanization-A view based on system coupling perspective. Tour. Trib. 2020, 35, 14-31.

2. Freya, H.D. Sustainable tourism: Sustaining tourism or something more? Tour. Manag. Perspect. 2018, 25, 157-160.

3. Zhao, L.; Fang, C.; Mao, C.L. Is the tourism driven urbanization hypothesis valid for China? An empirical study based on a linear and nonlinear test. Tour. Sci. 2016, 30, 22-38.

4. Wang, H.; Song, C.Y. Analysis on tourism urbanization. Econ. Probl. 2009, 10, 126-129.

5. Zmyślony, P.; Kowalczyk-Anioł, J. Urban tourism hypertrophy: Who should deal with it? The case of Krakow (Poland). Intl. J. Tour. Cities 2019, 5, 247-269. [CrossRef]

6. Hu, Z.P.; Huang, X.X.; Fu, C.; Yu, D.J. The quantitative comparison and evolutionary analysis on interactive coupling among tourism, urbanization and ecological environment in Poyang Lake area. Res. Environ. Yangtze Basin 2015, 24, $2012-2020$.

7. Joseph, E.M. The socio-economic and environmental impacts of tourism development on the Okavango Delta, north-western Botswana. J. Arid. Environ. 2003, 54, 447-467.

8. Ma, Y.F.; Zhang, C.H.; Liu, J.S.; Gao, Y.; Pang, W. Coupling with tourism: A new approach to sustainable development research. Tour. Hospit. Prosp. 2018, 2, 1-19.

9. Liu, J.S.; Ma, Y.F. The evolution and driving mechanism of the supply and demand coupling about tourism flow and destination system based on the genesis and system theory: Taking Xi'an as an example. Geogr. Res. 2017, 36, 1583-1600.

10. Xiong, J.X.; Wang, W.H.; He, S.H.; Yin, Y.; Tang, C.F. Spatio-temporal pattern and influencing factor of coupling coordination of tourism urbanization system in the Dongting Lake Region. Sci. Geogr. Sin. 2020, 40, 1532-1542.

11. Xiang, L. A study on the spatial and temporal differentiation of tourism-urbanization-ecological environment coordination in Yangtze River Economic Zone. Ecol. Econ. 2017, 33, 115-120.

12. Rong, H.F.; Tao, Z.M.; Liu, Q. Temporal and spatial evolution of the coupling coordination among tourism industry, urbanization, ecological environment in Southern Anhui Province. Res. Soil. Water Conser. 2019, 26, $280-285$.

13. Li, L.X.; Yang, Q.; Sun, C.C.; Xie, X.L. Coupling coordinated evolution and forecast of tourism-urbanization-ecological environment: The case study of Chongqing, China. Math. Probl. Eng. 2021, 2021,1-15.

14. Liu, J.S.; Li, C.; Tao, J.Q.; Ma, Y.F.; Wen, X.J. Spatiotemporal coupling factors and mode of tourism industry, urbanization and ecological environment: A case study of Shaanxi, China. Sustainability 2019, 11, 4923. [CrossRef]

15. Mullins, P. Tourism Urbanization. Int. J. Urban Reg. Res. 1991, 15, 326-342. [CrossRef]

16. Wang, D.P.; Yan, S. Preliminary research of tourism urbanization phenomenon-A case study on Turpan, in Xinjiang. J. Arid. Land. Resour. Environ. 2003, 17, 118-122.

17. Lu, L.; Ge, J.B. Reflection on the research progress of tourism urbanization. Geogr. Res. 2006, 25, 741-750. 
18. Liang, K.; Du, J.C.; Lv, W.Q. Analysis on spatial-temporal characteristics of the coupling coordinative degree between tourism industry and urbanization in Southwest China. Econ. Manag. J. 2014, 36, 125-134.

19. Mullins, P. Cities for pleasure: The emergence of tourism urbanization in Australia. Built. Environ. 1992, 1, 187-198.

20. Makowska-Iskierka, M. Spatial and morphological effects of tourism urbanization in the Łódź Metropolitan Area. Tourism 2013, 23, 33-42. [CrossRef]

21. Qiu, Y.Z. Study on tourism urbanization in minority areas. J. Southwest Univ. Natl. Humanit. Soc. Sci. 2005, 26, 26-28.

22. Mullins, P. Class relations and tourism urbanization: The regeneration of the Petite Bourgeoisie and the emergence of a new urban form. Int. J. Urban Reg. Res. 1994, 18, 591-608. [CrossRef]

23. Gladstone, D.L. Tourism urbanization in the United States. Urban Aff. Rev. 1998, 34, 3-27. [CrossRef]

24. Martins, J.C. Sun, sea and extended urban territories. In Proceedings of the Second International Conference of Young Urban Researchers, Lisbon, Portugal, 11-14 October 2011; pp. 1-9.

25. $\mathrm{Wu}, \mathrm{T}$.Y. Characteristics and mechanism of tourism urbanization in ethnic villages in remote and poor areas-Taking Miao Village in Xijiang as an example. J. Anhui. Agr. Sci. 2019, 47, 123-127.

26. Lu, L.; Yu, R.; Zhu, F.B. A research on the characteristics of tourism urbanization and mechanism of Huangshan Tangkou town from the perspective of sociology. Hum. Geogr. 2010, 25, 19-24.

27. Liang, P.Y.; Yu, J. An empirical study on the Silk Road heritage tourism-urbanization coupling coordination-Taking Shaanxi Province as an example. J. Northwest Norm. Univ. Nat. Sci. 2019, 55, 118-124.

28. Wang, S.J.; Fang, C.L.; Wang, Y. Quantitative investigation of the interactive coupling relationship between urbanization and eco-environment. Acta Ecol. Sin 2015, 35, 2244-2254.

29. Gao, N.; Ma, Y.F.; Li, T.S.; Bai, K. Study on the coordinative development between tourism industry and urbanization based on coupling model: A case study of Xi'an. Tour. Trib. 2013, 28, 62-68.

30. Wang, Z.F.; Huo, F.F.; Xu, S. Study on coupled development and regional differences between tourism industry and tourism environments in Hunan, Hubei, Chongqing and Guizhou. Econ. Geogr. 2018, 38, 204-213.

31. Gao, Y.; Ma, Y.F.; Liu, J.S. Study on the coupling coordinative development and types among tourism, urbanization and ecological system: A case study of Beijing-Tianjin-Hebei. J. Shaanxi Norm. Univ. Nat. Sci. Ed. 2016, 44, 109-118.

32. Geng, S.T.; Xie, Y.J. Research on coupling relation between tourism economy and ecological environment of china's sub-provincial cities. Urban Dev. Stud. 2013, 20, 91-97.

33. Gao, S.C. Analysis of the evaluation system about urbanization quality. Areal Res. Dev. 2016, 35, 33-39.

34. Deng, C. Spatial-temporal evolution analysis on interactive coupling among tourism, urbanization and ecological environment in Shanxi Province. Areal Res. Dev. 2018, 37, 85-89.

35. Cheng, Y.W.; Zhang, H. The study of Chinese tourism city judgment and classification based on the theory of urban function. Mod. Urban Res. 2014, 2, 104-109.

36. Zhang, G.H.; Zhao, W.S. The dynamic relationship, mechanism and regional differences of urbanization and touristization in China-Based on provincial panel data by PVAR Model. Bus. Manag. J. 2017, 39, 116-133.

37. Guo, X.Y.; Mu, X.Q.; Ming, Q.Z. Spatial coupling between rapid traffic superiority degree and tourist flow intensity in tourist destinations. Geogr. Res. 2019, 38, 1119-1135.

38. Gao, W.Q.; Li, Y.Z. Research on coupling coordination degree between tourism industry and urbanization of Changshan islands. Resour. Dev. Market. 2016, 32, 96-98.

39. Xu, H.G. A preliminary study on exploration of the dynamic patterns between urban development and urban tourism. Human Geogr. 2005, 20, 6-9.

40. Yang, C.P. Study on the relationship between urbanization and tourism development in Guizhou Province. Guizhou Soci. Sci. 2012, 265, 76-79.

41. Yang, Y.L.; Sun, G.N. Spatial-temporal analysis of the relationship between domestic tourism development and urbanization in China. Econ. Geogr. 2013, 33, 169-175.

42. Sheng, L.; Li, T.; Wang, J. Tourism and externalities in an urban context: Theoretical model and empirical evidence. Cities 2017, 70, 40-45. [CrossRef]

43. Zmyślony, P.; Kowalczyk-Anioł, J.; Dembińska, M. Deconstructing the Overtourism-Related Social Conflicts. Sustainability 2020, 12, 1695. [CrossRef] 